\title{
Facilitated Modelling with Discrete-Event Simulation: Reality or Myth?
}

\author{
Stewart Robinson ${ }^{a}$, Claire Worthington ${ }^{b}$, Nicola Burgess $^{c}$, Zoe J Radnor $^{d}$
}

${ }^{a}$ School of Business and Economics, Loughborough University, Loughborough, LE11 3TU, United Kingdom

${ }^{b}$ Lancashire Business School, University of Central Lancashire, Preston, PR1 2HE, United Kingdom

${ }^{c}$ Warwick Business School, University of Warwick, Coventry, CV4 7AL, United Kingdom ${ }^{d}$ Cardiff Business School, Cardiff University, Cardiff, CF10 3EU, United Kingdom

Corresponding author: Stewart Robinson, s.1.robinson@lboro.ac.uk, Tel: 44-1509-222432, Fax: 44-1509-223960

\begin{abstract}
Is it possible for discrete-event simulation to be used in a facilitated workshop environment? Over the last decade there have been various attempts to use simulation in this way, but we argue here that none have been successful in achieving a fully facilitated mode where the model is both developed and used in the workshop. We attempt to use a discrete-event simulation in a facilitated mode as part of a lean improvement workshop in a hospital setting. The model was successfully developed and used within the three day period of the workshop. Although the intervention was successful, we still had to build the model in the 'back-office', meaning that a fully facilitated mode was not achieved. The paper concludes by discussing how fully facilitated modelling with discrete-event simulation might be made possible; the answer is more about changing mind-sets than about technological challenge.
\end{abstract}

\section{Key Words}

Simulation, facilitated modelling, OR in health services 


\section{Facilitated Modelling with Discrete-Event Simulation: Reality or Myth?}

\section{Introduction}

Over the last decade there has been some interest in the use of discrete-event simulation as a tool for use in facilitated modelling. The key idea is to move away from the traditional mode of simulation use where much of the work is performed by the simulation modeller in the 'backoffice'. Instead, the aim is to involve the client much more deeply in the simulation work. Greater stakeholder engagement is seen as a means for improving the information flow from the client to the modeller and vice versa, ultimately leading to a better quality of model and a greater chance of a successful outcome. In particular, it is suggested that client involvement increases the credibility of the work and so the likelihood that the findings of the study will be implemented. This might be seen as a natural extension of Churchman and Schainblatt's (1965) mutual understanding position, which at the time was a vision of how to improve implementation success.

Since the time of Churchman and Schainblatt there have been many developments in discreteevent simulation, largely in line with developments in computing (Robinson, 2005). In particular, visual interactive modelling systems, which appeared in the 1980s, have facilitated closer engagement between the client and the modeller (Pidd, 2004). Alongside these developments, we have seen the emergence of problem structuring methods that lend themselves directly to a facilitated modelling approach; for examples see Rosenhead and Mingers (2001). Some have sought to draw on these developments to create a facilitated modelling approach that uses discrete-event simulation.

In this paper, we ask whether it is really possible to perform facilitated modelling using discrete-event simulation. In doing so we develop an understanding of facilitated modelling and particularly focus on previous work on facilitated modelling with simulation. We then describe a case example in which simulation is used in a 'facilitated' mode as part of a lean improvement workshop in a hospital setting. This case, as well as previous work, provides the basis for asking whether a facilitated modelling approach with simulation has really been achieved yet. We conclude by identifying that there needs to be a reduction in the complexity of a model and greater engagement and involvement of the client to develop a fully facilitated approach. 


\section{Facilitated Modelling and Simulation}

Franco and Montibeller (2010) discuss in detail the role of facilitated modelling in operational research. Facilitated modelling is contrasted with the traditional approach to operational research interventions, described as 'expert mode'. In expert mode the modeller aims to provide an objective analysis of the problem situation and to identify optimal, or at least good, courses of action. A key characteristic of expert mode is that much of the work, which may require detailed data analysis and model coding, is carried out without the client being present; it is, of course, recommended that there are regular meetings with the client.

According to Franco and Montibeller, although expert mode has been employed successfully on many problem situations, it is not always appropriate, for instance, when there is a lack of agreement on the nature of the problem situation and where there are multiple stakeholders with conflicting perspectives and objectives. The mode of facilitated modelling aims to address these shortcomings, primarily by the modeller working jointly with the client for the whole of the modelling intervention. The expert mode assumes that problems are real entities, the analysis needs to be objective, clients want optimal solutions, and implementation follows from scientifically rigorous work. In contrast, facilitated mode takes the perspective that problems are socially constructed, subjectivity is inevitable, clients want satisficing solutions, and implementation is enhanced by participation in the study.

The facilitated mode might be seen as synonymous with soft methodologies or problem structuring methods such as soft systems methodology (Checkland, 1981) or strategic options development and analysis (Ackerman and Eden, 2010). Clearly, such approaches lend themselves well to fully involving the clients in the work; indeed, they may even require full client engagement. Where the facilitated mode seems less applicable is when we move to 'harder' methods such as discrete-event simulation and optimisation. In general these methods require complex models and detailed data, and aim to provide an objective analysis leading to optimal (or good) solutions. These characteristics are an anathema to facilitated modelling and require much of the modelling work to be carried out in the 'back-office'.

System dynamics, however, provides an example of using a mathematically based technique in a facilitated mode. Early work in system dynamics recognised the need to involve the clients 
in the modelling, but it was in the 1990s that parallel activities in Europe and the USA developed the idea of group model building. Vennix $(1995,1996)$ used the term group model building to refer to the construction of a system dynamics model whilst working directly with a group of clients; here 'learning teams' are created in which people learn from each other to generate a shared perspective. At a similar time, Richardson and Andersen (1995) were developing system dynamics models through facilitated workshops with computer projection. There are many examples of system dynamics models being developed using the group model building approach, for instance, for business development (Vennix et al, 1996), for new housing development and urban renewal (Eskinasi et al, 2009) and for integrated sustainability assessments (Videira et al, 2010). Alongside these case studies, there has been a continuing focus on methodological developments, drawing upon the accumulated experience of many years of case study work (Rouwette et al, 2011; Rouwette, 2011).

Although system dynamics is a simulation approach with mathematical underpinnings, its underlying assumptions and methodology are quite different to those of discrete-event simulation (Tako and Robinson, 2010). As a result, ideas developed in the one field may not be directly transferable to the other.

It only requires a cursory investigation of the discrete-event simulation field to recognise that, as expected, the dominant modus operandi is the expert mode. Key simulation texts discuss the life-cycle of a simulation study (Banks et al, 2005; Law, 2007; Robinson, 2004). They all recognise the need for regular client contact, but in doing so assume that much of the modelling and analytical work will be carried out without the client being present. Robinson (2002) identifies the dominant modes of simulation practice in business and military simulation as a 'process of organisational change' and 'software engineering' respectively; the latter particularly requiring only very limited client involvement for many elements of the work. Pidd and Robinson (2007) extend this framework, but still identify the dominant approach to simulation as being software engineering or visual interactive modelling, neither of which requires continuous client involvement.

However, Robinson (2002) and Pidd and Robinson (2007) both recognise the potential for simulation to be used in a facilitated mode. The later paper splits this into two possibilities: model development through participative modelling and a facilitative approach to using (or 
experimenting with) the model. The key facets of simulation in facilitated mode are to develop an understanding of, and provoke debate about, the problem situation through the use of a quick-and-dirty model that is thrown away at the end of the intervention. The model is judged not so much on its accuracy, but on its usefulness for promoting debate and generating understanding. The modelling process itself is highly iterative, moving backwards and forwards between conceptualising the model, model coding and experimentation with the model. The clients are highly involved throughout the modelling process and as such might be better referred to as 'actors'. The prime skill of the modeller is not so much in software development or even modelling, but in managing the facilitated process.

Examples of simulation being used in facilitated mode have been reported in the literature. Possibly the earliest example is Robinson (2001) where he develops and uses a simulation to investigate the improvement of a university information systems user support help desk. The modelling started in expert mode, but due to a lack of good quality data, the simulation could not be used for objective analysis. As a result, the author ran a facilitated session with the clients in which the model was used to understand the functioning of the helpdesk and to debate possible improvements. The ideas that were generated were tested by changing and running the simulation model during the facilitated session in order to obtain an indication of whether they were likely to lead to an improvement.

Adamides and Karacapilidis (2006) describe a methodology for collaborative business process modelling that involves a facilitated approach for generating a process map and reporting the results of a simulated version of that map. They develop a web-based information system through which multiple stakeholders can interact and collaboratively create the process map. The simulation itself is developed off-line by an expert modeller. The results of model runs are then reported back to the stakeholders with the aim of providing indications, rather than predictions, of the performance of the business process.

den Hengst et al (2007) report on a study in which they investigated the cargo flows at a Dutch airport. Their approach is described as 'collaborative simulation' which combines discreteevent simulation with group support. The distinguishing feature of their approach was to run a series of group sessions over the life-cycle of the project to formulate the problem, validate the model, and demonstrate and present the findings from the model. The simulation itself was detailed, requiring four months to be developed. As a result, the model ran slowly and it could 
not be used live in meetings. A cut-down version of the simulation was created for rapid simulation runs in meetings. Experimentation with the model was primarily used for generating understanding and insight, and not for optimising the process. den Hengst et al make the following observations regarding the future development of collaborative simulation:

- The design of the simulation model: the model has to be understood by non-experts, be a satisfactory representation of reality, be rapidly adaptable, and run in seconds.

- Data collection: the time to collect data could be reduced by using expert estimates generated in a collaborative workshop.

- Model building: the time required to build the model could be reduced by using reusable model components.

More recently, Tako et al (2010) describe the PartiSim (Participative Simulation) framework for developing and using discrete-event simulations in healthcare. The framework consists of six stages: initiate the study, structure the situation of interest, specify the study objectives, develop the simulation model, experimentation and implementation. The novelty in the approach lies in the participative approach for the second, third, fifth and sixth stages of this process. This is achieved through four facilitated workshops. The first two of these workshops adopt an approach based on soft systems methodology. In a similar vein, Barjis (2011) proposes a collaborative, participative and interactive (CPI) modelling approach using simulation. He distinguishes these three terms defining collaboration as cross disciplinary working, participation as the involvement of users, and interaction as the tools that enable collaboration. Although an example of a CPI workshop is presented, the idea is a work-inprogress and as yet a simulation has not been used as part of the approach.

Beyond these studies, there appears to be very little written on facilitated modelling using discrete-event simulation. There are a number of studies that combine discrete-event simulation with problem structuring methods (Lehaney and Paul; 1996; Lehaney et al, 1999; Kotiadis and Mingers; 2006; Kotiadis, 2007; Sachdeva et al, 2007). Although these studies adopt a facilitated approach to the 'soft' aspects of the work (e.g. understanding the problem situation), they do not attempt to adopt a facilitated approach to the whole study, especially the simulation elements of the work. These studies could best be described as adopting a 
multimethodology rather than a facilitated modelling approach (Mingers and Brocklesby, 1997).

It could be argued that all of the examples of simulation being used in facilitated mode described above meet at least some, if not all, of the assumptions of facilitated modelling described by Franco and Montibeller (2010):

- Problems are socially constructed entities: in the PartiSim framework (Tako et al, 2010) managers' subjective and differing perceptions of a problem are accommodated through soft systems methodology based workshops, with the aim of creating a joint problem definition.

- Subjectivity is inevitable: subjectivity is accounted for in collaborative model development (Adamides and Karacapilidis, 2006; Tako et al, 2010) and through facilitated workshops in which ideas for improvement are run through the model and the outcomes are interpreted by the group (Robinson, 2001).

- Clients want satisficing solutions:den Hengst et al (2007) run simulation experiments with a view to generating insight and understanding, and not for optimisation.

- Implementation is enhanced by participation in the study: a key motivation of the PartiSim framework (Tako et al, 2010) is to improve the implementation of modelling studies in healthcare by managers participating in the studies.

What none of the examples achieve, however, is the key characteristic of facilitated modelling, namely, that the modeller works jointly with the client for the whole of the modelling intervention. Specifically, in none of these examples was the simulation model actually built while the client was present. This is primarily because of the time required to develop the model. Instead, the focus for the facilitated approach is on the use of the model once it is developed, i.e. facilitated use of the model as identified by Pidd and Robinson (2007). In some instances facilitated workshops are used for defining the problem and the objectives of the study, for process mapping and for validating the model, but never for model building.

\section{Facilitated Modelling using the SimLean Approach}


Robinson et al (2012) discuss the common motivation of simulation modelling and lean, that is process improvement, and identify how simulation and lean might be used together. In doing so they develop the SimLean approach which distinguishes three ways in which discrete-event simulation can be used around lean improvement events. Before or during an event a simulation can be used to educate participants in key principles of lean relating to flow (SimLean Educate). Also during an improvement event, a simulation can be used to create a dynamic process map of the system under investigation and to debate potential changes to the system (SimLean Facilitate). Following an event, a detailed simulation can be used to accurately evaluate the improvement ideas that are generated (SimLean Evaluate). This third use for simulation is very much in line with Franco and Montibeller's (2010) expert mode, while SimLean Educate and Facilitate are closer to their facilitated modelling mode. The educational approach facilitates a generic discussion and learning around lean practices using a standard simulation model that is not specifically of the participants' system. A detailed description of SimLean Educate can be found in Burgess et al (2011). SimLean Facilitate uses a simple model of the participants' system to facilitate a discussion that aims to engender a better understanding of the system and to identify potential improvements.

Our focus in this paper is on SimLean Facilitate as an example of facilitated modelling using discrete-event simulation. We do not specifically focus on the links between simulation and lean or the details of the other elements of the SimLean approach. These are discussed in detail in Robinson et al (2012).

We now describe a case example in which we aimed to use simulation in a facilitated modelling mode. The case example involves a lean improvement event that took place in December 2010 at a large teaching hospital in the north west of England. For reasons of confidentiality we shall refer to it as Hospital Y. The SimLean team was invited to participate in the event and to use simulation in a facilitated mode to support the workshop.

The aims of the intervention were twofold: to generate understanding and discussion around the problem situation in order to help identify improvements (problem-solving); and to test SimLean Facilitate in a real decision-making context (research element). For the second aim we were particularly interested in identifying ways in which the SimLean Facilitate approach could be improved. The intervention was therefore conducted as an in-depth single case study (Yin, 1994) conducted as an action research intervention (Montibeller 2007). Action research 
was adopted in which the problem-solving element was addressed through simulation, in a facilitated mode, and the research element was carried out by observing the workshop and reflecting on the outcomes (McKay and Marshall, 2001; Montibeller, 2007). In order to achieve this one researcher developed the simulation and used it in the workshop to facilitate a discussion around the problem situation. Meanwhile, two further researchers observed the workshop, making notes on the process and outcomes, but with minimal intervention in the workshop itself. At the end of the intervention the participants were asked to complete a brief evaluation which solicited their views on the use of simulation in the workshop. The combination of facilitation, observation and evaluation meant that there was triangulation and validity with the data collected (Yin, 2007).

Below we describe the context of the case study, the running of the lean workshop over two days, the simulation model that was developed and how it was used in the workshop, and the outcomes of the facilitated modelling intervention. This description outlines the sequence and nature of the activities we performed for using simulation in a facilitated mode. Based on the findings from this action research intervention, section 4 reflects on the requirements for using simulation in a fully facilitated mode.

\subsection{The Context}

The focus of the lean improvement event was on the ophthalmology outpatients clinic. Although the ophthalmology department performed well on national performance measures, there was a severe problem with patient waiting times. Patients often waited for lengthy periods in crowded waiting rooms.

A key problem was that clinics regularly started late, primarily due to the poor punctuality of the doctors. This meant that clinics persistently overran and as a result the nurses were forced to stay on and work overtime. Nurses are not paid for overtime, but have the option to take time-off in lieu. However, due to the problems with the clinics, the nurses were rarely able to take this time off for fear of exacerbating the problems further. It is not a surprise that the morale of the nursing and administrative staff in the department was very low and they felt there was little they could do to improve the situation.

\subsection{The Lean Workshop}


The two day lean workshop was run by the lean improvement team at Hospital Y. It was split between two all day sessions on the Monday and Wednesday in the same week. The participants in the workshop were a Hospital Y Lean Facilitator, the Appointments Manager, the Receptionist, a Matron, two Nurses and the Ophthalmology Directorate Manager who was also Acting Assistant Director of Operations for Hospital Y (he was only able to attend for about 30 minutes on each of the two days). The SimLean team at the workshop consisted of a modeller (Worthington) who carried out the simulation work and two other researchers (Burgess and Robinson) whose role was to observe the workshop. It is notable that there were no doctors involved in the workshop, despite the fact that they had been invited. Their absence only helped to further damage the morale of the nurses and administrative staff at the beginning of the workshop.

Seven days before the workshop we held a set-up meeting with the Lean Facilitator and Ophthalmology Directorate Manager. This was an opportunity to learn more about the context and the requirements for the workshop and the use of SimLean Facilitate. It was also an opportunity for the staff at Hospital Y to learn about how the simulation would be used during the workshop. The outcome of this meeting was an outline programme for the two day lean event. The activities performed during the two days of the workshop are now described.

\subsection{Workshop Day 1}

The first day started with an overview of the issues faced by the staff with the current process. This was followed by a brief introduction to simulation through SimLean Educate (Burgess et al, 2011; Robinson et al, 2012). A standard model of a theatres process was used to demonstrate how a simulation works and to show how the model could help understand and improve the flow of patients through a hospital process. Although SimLean Educate is normally used to teach key lean lessons on how to improve flow, this was not the aim on this occasion; largely for reasons of time.

The next step was to go to see and experience the process; referred to in lean terminology as going to the 'Gemba'. Each participant in the workshop, including the SimLean team, went to the ophthalmology department and individually followed a patient through the clinic. This proved very instructive in understanding the patients' experience of the clinic. Table 1 outlines 
the experience of one of the patients. Albeit one of the worst examples that was observed on the day, with over two hours of waiting time, our understanding is that this level of waiting was not particularly unusual.

Table 1 A Patient's Journey through the Ophthalmology Clinic

\begin{tabular}{llc}
\hline \multicolumn{1}{c}{ Time } & \multicolumn{1}{c}{ Activity } & Duration \\
\hline 10.40 & Arrived at reception, no wait & \\
$10.40-11.07$ & Waited in waiting room 1 (waiting room full) & 27 \\
11.07 & Called for vision test, asked to read letters & 0.5 \\
11.08 & Walked round to waiting room 2 & 0.5 \\
$11.09-12.07^{*}$ & Waited in second waiting room (waiting room full) & 58 \\
$12.07-12.20$ & Visual fields test & 13 \\
$12.20-12.45$ & Waited (in waiting room 2) & 25 \\
12.45 & Patient called, but she reports she has already had the scan & 0.5 \\
$12.46-13.05$ & Patient returned to waiting room 2 and waits & 19 \\
$13.05-13.10$ & Patient with Doctor & 5 \\
13.10 & Patient went to reception where there was now a queue... & \\
\hline Total time in system & 148.5 \\
Total time waiting & 129 \\
Total time in activity & 19.5 \\
\hline
\end{tabular}

*At 11.50 a nurse announces to the packed waiting room that there is 1.5 hour delay on clinic times. It later transpires that the doctor had arrived 1.5 hours late for the clinic.

Following lunch, the workshop participants discussed their findings and then moved onto mapping the process. Because of their limited experience with process mapping the final process map, as shown in figure 1, was primarily drawn by the Lean Facilitator. This did not help to develop a sense of ownership of the map, but seemed necessary to get the process map completed. Once the map was drawn the participants were asked to estimate the minimum, modal and maximum times for each of the key activities, including the time spent in queues. The values are shown above and below the boxes in figure 1. The activity times were used as data inputs to the simulation model. It was clear, however, that these values did not match those experienced by the patients that were followed earlier in the day. In particular, the maximum values underestimated the queuing time experienced by patients such as the one in table 1. When challenged, the participants' response was that the clinic was understaffed and that nurses were distracted with triage and answering phones. On the other hand, they also felt that this was not abnormal.

Figure 1 Process Map for the Ophthalmology Clinic 


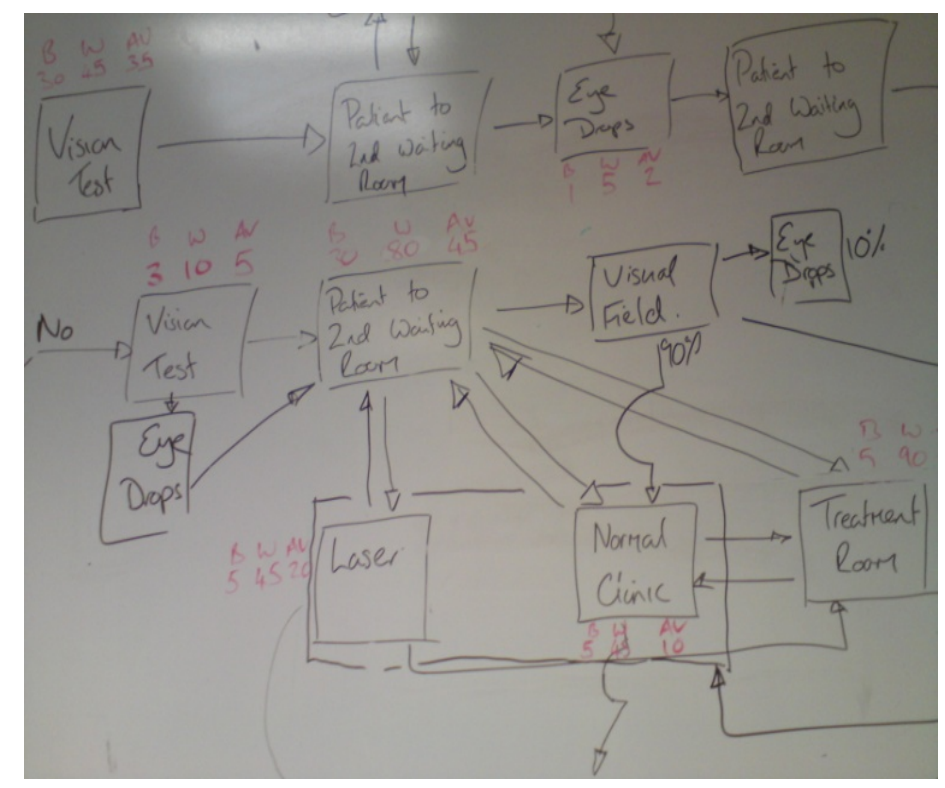

Further discussion ensued around the variety in patient pathways, which was less diverse than the staff initially believed, and the way in which appointments were set-up for the patients. At this point the workshop ended for the day.

\subsection{The Simulation Model}

On the Tuesday between the two workshop sessions the simulation model was developed using the SIMUL8 software (www.simul8.com accessed May 2012). The total time for building the model was in the region of 4-5 hours. The model, shown in figure 2, represents the process flow as set-out on the process map created during the first day of the workshop. The simulation display was designed in a slightly different fashion to the process map in order to highlight the extent to which patients have to wait. This was achieved by displaying all the queues in two waiting areas, and so replicating the two waiting areas in the real process. 


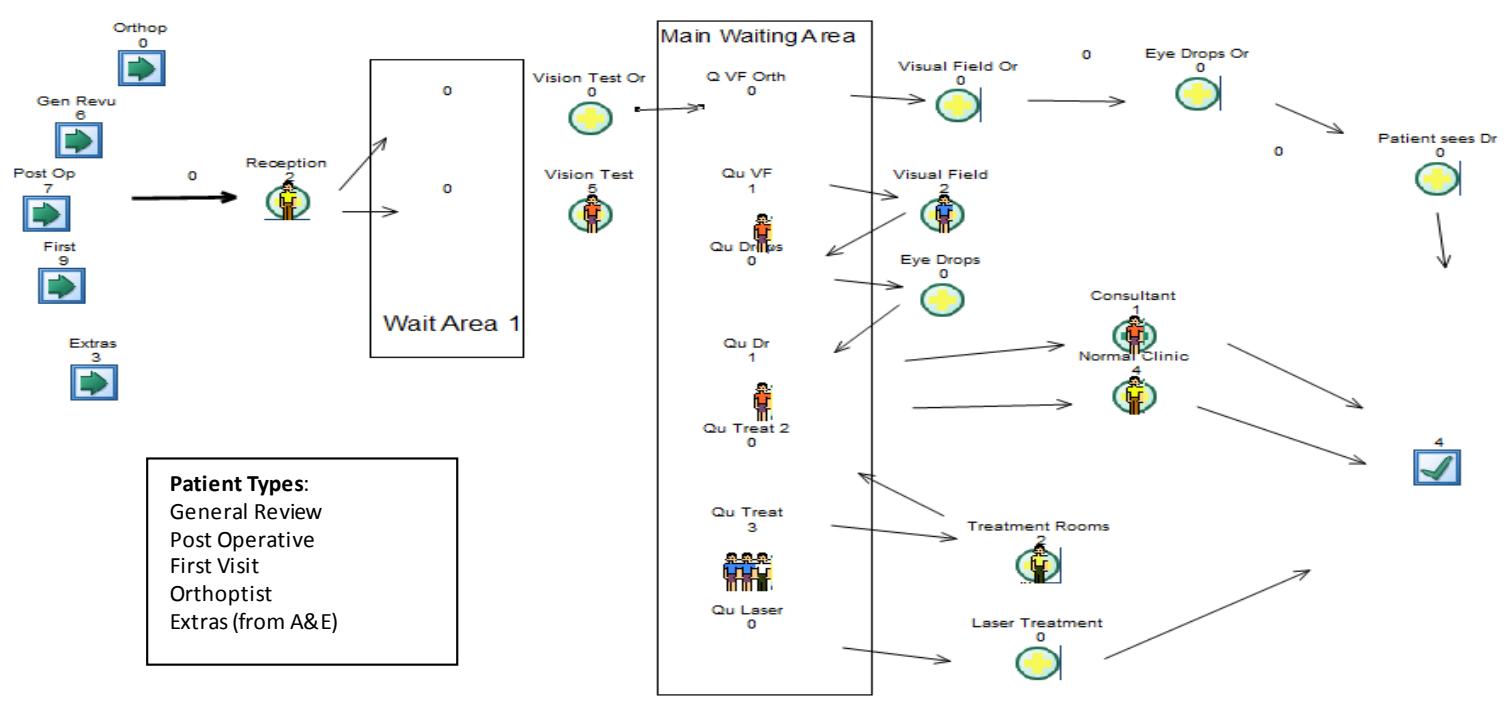

The simulation shows the five main groups of patient types that attend the clinic. On arrival they report at reception and then wait for a vision test. Following the vision test, the patient then waits for further tests, treatments or consultations, before leaving the clinic. The detail in the model is limited. The patient type is tracked through the model, with this impacting on the route the patients take through the tests, treatments and consultations. There is some use of percentage splits to route patients through the model. For instance, ten percent of patients go to receive eye drops after the visual field tests. These percentages were derived either from appointment data or from the expert opinion of the workshop participants.

Arrivals are modelled as appointments with a specified number of patients of each type arriving at pre-specified times. All activity times are sampled using a triangular distribution based on the estimated times on the process map (figure 1). Because of inaccuracies in the estimated data, these timings had to be adjusted to generate representative behaviour in the model. This might be referred to as 'model calibration' (Robinson, 2001) or even 'data fudging'.

The key reports generated by the model were the distribution and mean of the time in system, by patient type, and the number of patients in the waiting rooms over time. Both outputs are generated automatically by the simulation software.

\subsection{Workshop Day 2}


The second day of the workshop started with a recap of the first day. At this point it was very evident that the participants felt there was little they could do to improve the situation and that without the doctors engaging with the improvement process, there was no scope for improvement; after all, the participants believed that the problem solely centred around the doctors' tardiness in arriving for the clinics. It was at this point that the simulation model was introduced, projected through a large television screen. Immediately the researchers observed a change in the participants' body language, they sat forward, took an interest and engaged in the discussion.

The discussion around the model then went through four phases, each taking roughly 30 minutes, as follows.

Model Understanding: what is the model doing? The model was briefly explained to the participants and the simulation run with the animation at a speed where the movement and queuing of patients could easily be seen. The participants then proceeded to ask a series of more detailed questions which centred on understanding the workings of simulation generally and of the ophthalmology clinic simulation in particular.

Face Validation: does this look like what happens in the ophthalmology clinic? The participants then moved on to thinking about whether what they were observing in the simulation model was similar to what happens in the actual clinic. This was not a detailed validation of the model in which white-box and black-box validation were carried out (Robinson, 2004). Instead, it focussed on the animation and watching the flow of patients and the build-up of queues; a form of face validation (Sargent, 2011; Law, 2007). There was a general sense that the simulation looked reasonable with participants noting that the queues looked quite similar to those they experienced on a day-to-day basis.

Problem Scoping: what is causing the problems in the ophthalmology clinic? In this phase the discussion largely moved away from the simulation itself and started to focus on the specific problems they were encountering. Rather than disengaging because the problems were 'the doctors' fault', the participants engaged in a discussion around what were the other causes of the problems they were encountering. During this phase it was clear that the simulation had acted as a catalyst for the discussion. Seeing, for the first time, a helicopter view of their 
process working enabled them to identify issues that had previously remained hidden because they are normally involved in the detail of only their part of the process. One particularly powerful learning point was that they moved away from the belief that every patient's requirements was so unique that they had to be treated in a completely different way to any other patient, and that they did not know what a patient would require until they arrived. Following the simulation, they could now see that many patients followed common pathways through the ophthalmology clinic, opening up the potential to actively manage patient flow, a view that had previously been dismissed

Improvement: what could we do about it? The participants then started to think about how they could improve upon the current situation. They accepted that they could not alter the doctors' behaviour directly, but they realised they could take action to reduce patient waiting and in so doing to make their working life more comfortable. They also recognised that if they improved the elements of the patient experience over which they had control, this might put pressure on the doctors to alter their behaviours.

The key idea that emerged from this discussion was to perform two eye tests (the vision test and the visual field test) at the same time rather than to split them across two consultations, with patients waiting between them. This might make a significant difference as all orthoptist patients and 20 percent of all other patients required both tests. This change would reduce overall waiting by effectively removing one process step for these patients. During the lunch break the Matron and the Lean Facilitator went back to the department to investigate whether it might be possible to reconfigure the room where the visual fields tests are performed so that both tests could be carried out in the same room. They measured the room and concluded that this was possible.

Also, during the lunch break, we were able to change the model to reflect the proposed combining of the eye tests (figure 3). The model indicated that the time patients would wait for these procedures would be reduced by around ten percent as a result of this change. Given the nature of the model, this could only be taken as an indicative change and not as an accurate result. It did, however, provide the participants with further confidence that the proposed change would be effective.

Figure 3 Simulation Model of the Revised Hospital Y Ophthalmology Clinic 


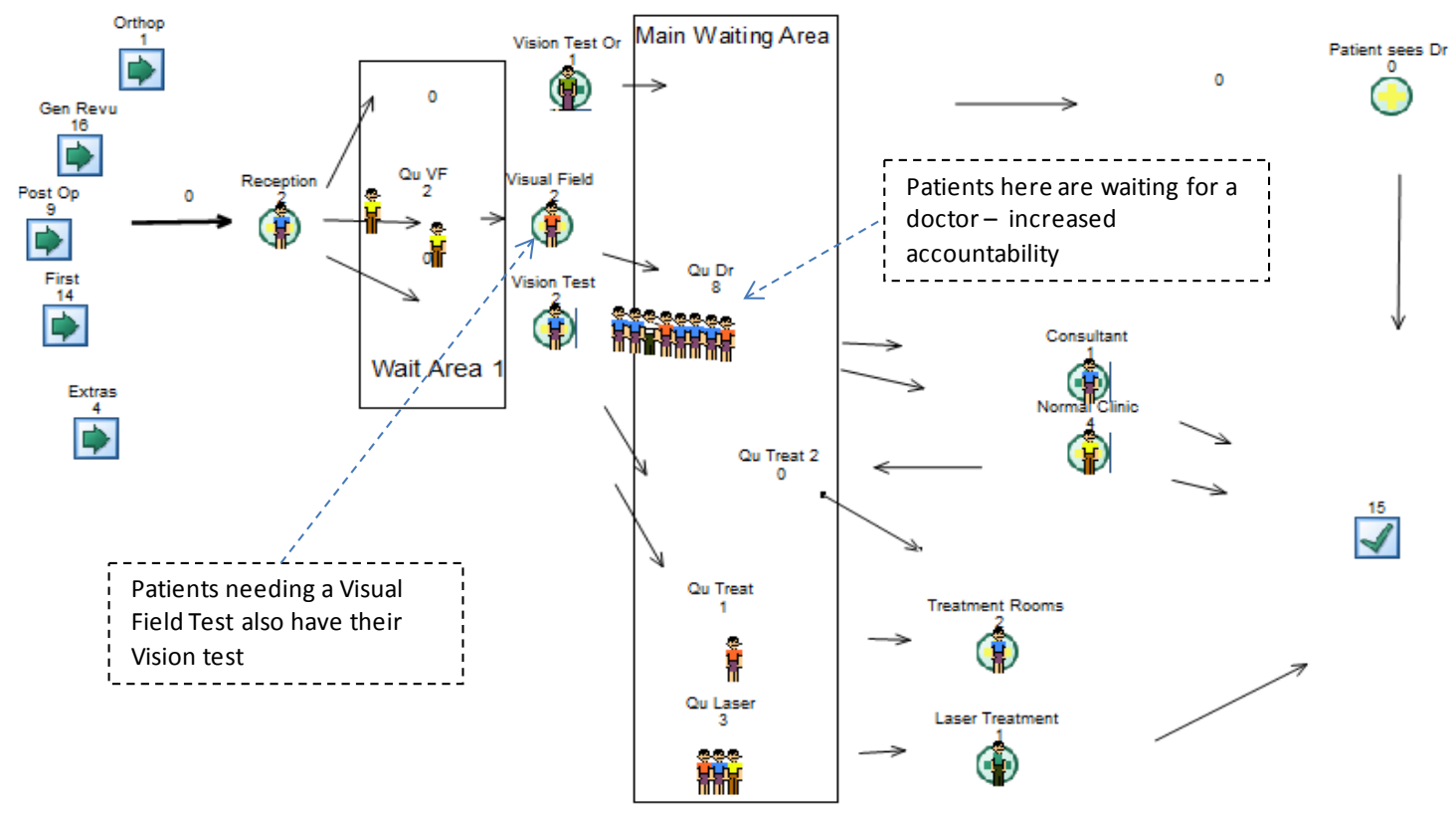

The other result of the combined eye testing was that the queue for the doctors would increase because of the improved flow of patients through the eye tests. This was seen favourably as it would potentially put pressure on the doctors to start their clinics on time. In the longer term this would be necessary to improve the performance of the whole system, delivering a better experience for patients and staff.

The workshop concluded with a final briefing with the Ophthalmology Directorate Manager at which it was agreed that the recommendation to combine the eye tests would be put forward for implementation. It was also agreed to mitigate the shortage of nursing staff by investigating the option of training nurses from other departments to work in the ophthalmology clinic.

\subsection{The Outcome}

The first aim of this intervention was to generate understanding and discussion around the problem situation in order to help identify improvements (problem-solving). It is clear that the immediate impact of using the simulation model in the workshop was to engage the participants in a meaningful discussion about the problems they were encountering and possible ways that they could improve the situation. Before the simulation was presented, the workshop participants were more focussed on who else could be blamed for the problems, which 
generated a feeling that there was little that could be done to improve the situation. The lean facilitator for the workshop said afterwards that the simulation was the turning point in the discussion.'

In the post workshop evaluation all the participants stated that they found the simulation interesting. The Appointments Manager stated that '... it worked really well, it was good seeing the patient flow.' They also found the dynamic simulation more useful than the static process map: 'we talked a lot more about the model than about the map on day 1.' When asked whether the simulation had helped identify changes to the process there was a general consensus that it had: 'yes demonstrated options' (Matron) and 'definitely helps see the bigger picture' (Nurse). The simulation was seen to have had a high impact on the discussion because 'it got me thinking about the process and challenging it.'

Following implementation of the change to the eye test, the ophthalmology clinic actually saw a $15 \%$ reduction in total patient waiting times. As a result, staff were interrupted less by patients who are stressed by excessive waiting times and doctors were no longer able to blame nurses for not having patients ready for their consultation. As such, the intervention not only identified a potential improvement to the ophthalmology clinic, it also led to an actual improvement once the change was implemented.

It is apparent that using a simulation for the problem-solving element of the intervention was a success. This in itself is not a surprising outcome as simulation has been used to help successfully intervene in problem situations for many decades. The outcome is of more interest because, given the time and data that were available, it was not possible to develop a simulation that modelled the full detail of the situation or that generated accurate results . Rather than seeing this as a failure of the intervention, it was in fact the basis of the intervention's success. Indeed, it was the willingness to rapidly generate a very simplified model that made the use of simulation in the workshop possible. The success of this study lends support to Roy's argument for a decision-aid science rather than a decision science (Roy, 1993). The latter is founded on models with a high level of fidelity ('realism'), while the former seeks to use models to 'enlighten and scientifically accompany decision-making processes.' Phillips (1984) describes such models as 'requisite', that is models 'whose form and content are sufficient to solve a particular problem.' 
As with any action research we must be careful not to claim that our findings are applicable to all situations. What we have demonstrated is that a simple simulation model used in a facilitated workshop can generate understanding and discussion around a problem situation and lead to a real improvement. However, from a single case we cannot determine the specific characteristics of the problem situation, the workshop or the simulation model that might make a facilitated approach viable and successful. Certainly, we do not expect facilitated modelling with simulation to be appropriate for all contexts.

The second aim of this research was to test SimLean Facilitate in a real decision-making context and to identify ways to improve the approach. This is discussed in the next section by reflecting on our experience with SimLean Facilitate at Hospital Y and discussing whether facilitated modelling with discrete-event simulation is really possible.

\section{Discussion: Is Facilitated Modelling with Discrete-Event Simulation Really Possible?}

Following our experience with the workshop at Hospital $\mathrm{Y}$ we now discuss whether this work truly presents an example of facilitated modelling with simulation. We also discuss the requirements for rapid simulation modelling and for moving to a fully facilitated mode of modelling with discrete-event simulation.

\subsection{To What Extent is the Hospital Y Study an Example of Facilitated Modelling?}

Figure 4 outlines the key phases of a simulation study, as described by Robinson (2004). It shows four key activities: conceptual modelling, model coding, experimentation and implementation. These are carried out iteratively throughout the life-cycle of a simulation study; hence the double arrows between each activity. Meanwhile, data collection and analysis, and verification and validation are performed continuously during the study as part of each of the four activities listed above.

Figure 4 Comparison of Expert, Facilitated and 'Pseudo-Facilitated' Mode of Modelling 


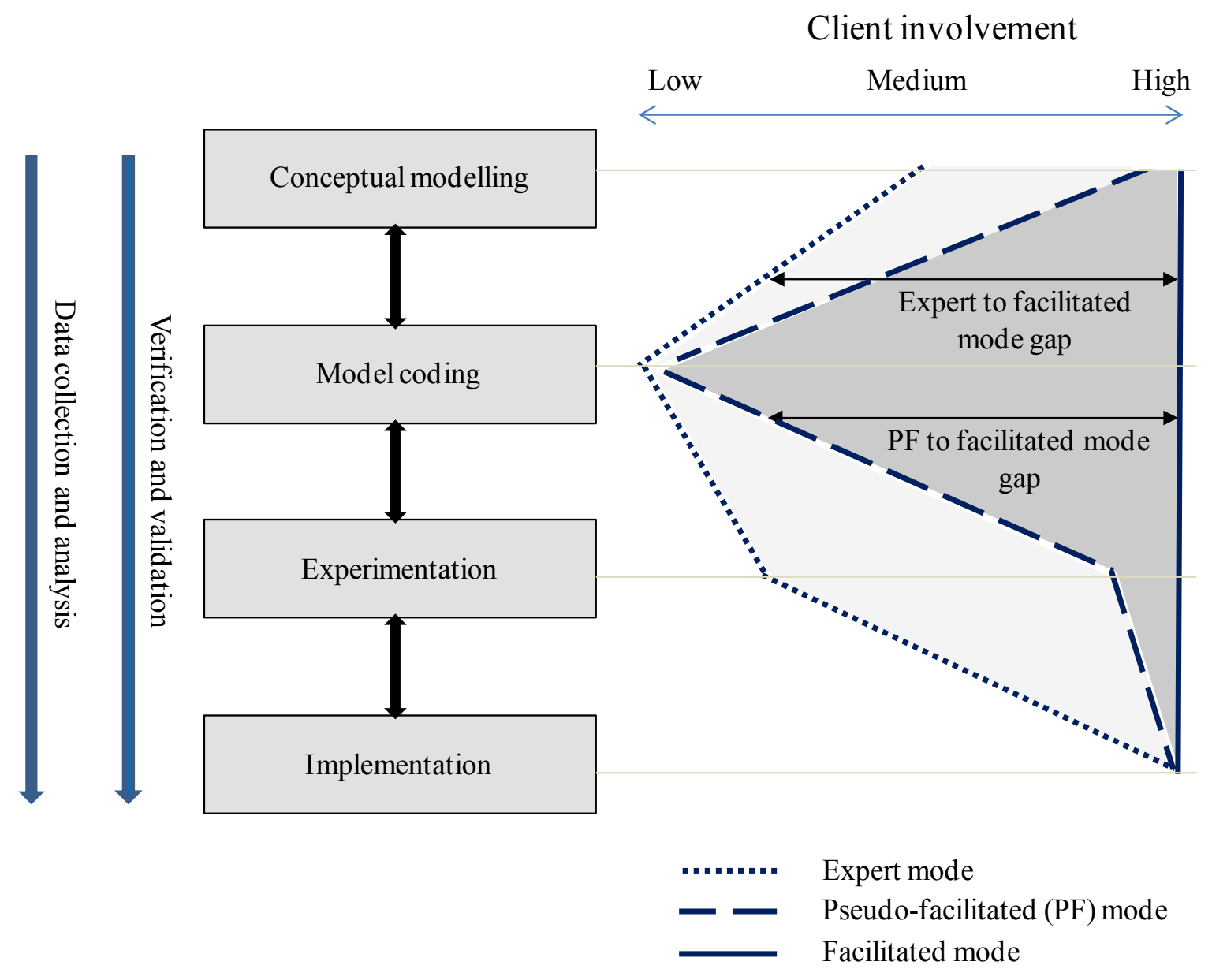

On the right of figure 4 the level of client involvement during each activity is shown. In the traditional expert mode for simulation, client involvement is at a medium level during conceptual modelling where they are involved in regular meetings to help define the nature of the problem and the model. They have almost no involvement in model coding, except to occasionally see the model during its development and to comment on its apparent validity. Client involvement in experimentation is higher than this, but again it is limited to meetings at which results are presented and further simulation runs are defined; the simulation runs themselves are performed by the modeller away from the client. Because the clients typically take sole responsibility for the implementation of the findings from the study, their involvement in this activity is identified as high in figure 4.

In contrast, Franco and Montibeller's (2010) facilitated modelling mode would require high client involvement for all four activities; as shown by the vertical line on the right of figure 4 . There is, therefore, a significant gap between traditional simulation practice and facilitated modelling, shown as the expert to facilitated mode gap in figure 4. 
Reflecting on the Hospital Y study, we might identify the level of client involvement as being somewhere between these two extremes. Client involvement was much higher than in expert mode during conceptual modelling, primarily because the clients defined the process map which formed the basis of the simulation. There is little or no increase in client involvement in the model coding activity which was still carried out away from the workshop participants, although they were involved in the validation of the model. With the exception of some preliminary runs, the majority of the experimentation with the model was carried out during the second day of the workshop with the clients present. Implementation was again the responsibility of the client. So the pattern that emerges is one of near full facilitated mode in three of the four simulation activities, but the expert mode was still employed for model coding. Hence, we describe this as 'pseudo-facilitated' mode and highlight the gap between pseudofacilitated modelling and facilitated mode.

An investigation of the previous examples of facilitated modelling with simulation described in section 2 shows a very similar pattern; for instance, the studies of the user support help desk (Robinson, 2001) and the cargo flows at a Dutch airport (den Hengst et al, 2007). Most involve some form of collaborative or participative approach to conceptual modelling and experimentation. None involve the client in the model coding. As such, none of these examples, or our experience, can be described as fully facilitated modelling. The findings of this research, therefore, continue to illustrate the challenges of a fully facilitated use of simulation.

\subsection{Requirements for Rapid Simulation Modelling}

Where the Hospital Y study differs from previous pseudo-facilitated modelling studies with simulation is in the speed with which the simulation was developed. We would argue that providing a working model within two days of specifying that model (through a process map), increases the sense of engagement with, and ownership of, the model. It also reduces the cost of modelling and enables simulation to be part of rapid improvement activities such as a lean improvement workshop. In the case of the Hospital Y study we benefitted from having a day between the two workshop sessions in which we developed the simulation model. However, the actual time required to develop the model meant that we could have developed it in the 
evening between two consecutive workshop days if necessary; although this would have placed quite some pressure on the modeller.

In this case, rapid modelling was achieved by creating a very simplified model. The detailed complexity of the model was deliberately kept to a minimum. Based on our experience, table 2 outlines the detailed complexity we would recommend for the context of our study, that is, lean improvement in health services. These requirements would need to be adapted depending on the context of the facilitated modelling work.

Table 2 Requirements for Rapid Simulation Modelling in the Context of Lean Improvement of Health Services

\begin{tabular}{lll}
\hline \multicolumn{1}{c}{ Model Element } & \multicolumn{1}{c}{ Detail } & \multicolumn{1}{c}{ Complexity } \\
\hline Entities & Arrivals & $\begin{array}{l}\text { Time based profile or appointment based } \\
\text { Early/late/do not attend } \\
\text { Batched arrivals } \\
\text { Patient type } \\
\text { First/repeat patient } \\
\text { Priority }\end{array}$ \\
& Attributes & FIFO, LIFO, By attribute \\
Queues & Capacity & Queue discipline/priority \\
& Minimum time in queue & Specify distribution \\
\hline Activities & Number of & Specify distribution or by patient type \\
& Time & Percentage or by attribute \\
& Routing & Fixed \\
Distributions & Types & Negative exponential \\
& & Triangular \\
\hline
\end{tabular}

Our aim is to be able to develop the model using the menus provided by a simulation software package with little or no coding beyond setting and changing attribute values. Inclusion of resources, for instance, can require quite complex modelling and coding. Hence, in these requirements there is no allowance for modelling resources such as doctors, nurses or equipment. In general, we would expect that the results would be generated by the standard facilities of the simulation software.

It is very easy to identify details that could be added to those in table 2 . These will almost certainly be identified as a means of generating a more accurate model. However, each additional level of complexity requires further data and further modelling time. By adding such details it is quite easy to negate the aim of developing the model rapidly. As such, the 
desire for 'model detail creep' should be resisted. This is challenging given that the mind-set of modellers and clients is generally to ensure robust levels of accuracy.

\subsection{What is Required to Move to Fully Facilitated Modelling with Discrete-Event Simulation?}

The discussion above demonstrates that fully facilitated modelling with discrete-event simulation has yet to be achieved. Whilst conceptual modelling, experimentation and implementation can all be carried out with the client fully involved, model coding still presents more of a challenge. If the challenge of model coding with client involvement cannot be met, then our conclusion is that fully facilitated modelling with discrete-event simulation is not, and never will be, possible.

In section 2 we see that den Hengst et al (2007) make three recommendations for developing what they term collaborative simulation: improving the design of the simulation model, collecting data in a collaborative workshop, and reducing model building time through component reuse. The SimLean Facilitate approach goes some way to addressing these requirements, particularly by directly generating the simulation from a process map created by the workshop participants, by using data estimated by the participants, and by creating a simple model that runs quickly and is easily adapted. This aids ownership of the model, understanding of the model and facilitated use of the model in a workshop.

The third recommendation of den Hengst et al is that the time required to build the model should be reduced by using reusable model components. This is suggesting a technical solution to the problem of the time required to build a model. We would offer an alternative solution which is to build a much simpler model. Note that den Hengst et al also resorted to this approach after having developed a very detailed model.

The benefits of simple models have long been discussed by authors such as Innis and Rexstad (1983), Ward, (1989), Salt (1993), Chwif et al (2000), Lucas and McGunnigle (2003), and Thomas and Charpentier (2005). Their key benefits are that they can be developed faster, are more flexible, require less data, run faster and the results are easier to interpret since the structure of the model is better understood. The disadvantage is that they are in most cases less accurate. 
Because of their lower level of fidelity, the use of simple models requires a change in worldview regarding the purpose of the model. Discrete-event simulation modellers are typically engrained in an expert mode of modelling. This requires that detailed and accurate models are developed for a scientifically rigorous analysis to proceed that will identify good solutions. Since simple models normally provide only rough approximations to the real world, they are rarely suited to the expert mode. To move to a facilitated mode, the modeller needs to be comfortable with a worldview in which the simulation focuses on facilitating understanding and debate within a group, with a view to identifying improvements, and not on generating predictions of system performance. A key issue is whether discrete-event simulation modellers are willing and able to change to this worldview. The basis for achieving this might be training programmes in simulation (and operational research more generally) that do not only discuss the technical requirements for simulation modelling and analysis, but also the methodological elements. In particular, training in the motivation and approaches of problem structuring methods could help change mindsets towards a more facilitated approach.

Just creating simple models, however, is not sufficient to move to a fully facilitated mode of modelling with simulation. As demonstrated by the Hospital Y example, the model was still developed without involvement from the client. How could the client actually be involved in generating the model code? For this, we do offer a technical solution. Given that we propose a very limited and tight definition of what can and cannot be modelled in a specific context, the process map could be directly populated with the data and rules required to generate the simulation model. If the process map is generated in electronic form, rather than using pen and paper, then workshop participants could be involved in entering the data and rules. The process map, data and rules could then be converted into a simulation at the touch of a button. This approach could be further enhanced if the process map could be generated in a workshop using software that supports group facilitated process mapping, entry of data and rules, and generation of a simulation model. This would provide a seamless environment for specifying, generating and running the simulation model. Facilities for each of these elements already exist, for instance, collaborative process mapping (Adamides and Karacapilidis, 2006) and many simulation software tools link with process mapping software (e.g. Microsoft Visio). However, we do not know of a tool that fully supports all elements of this process.

\section{Conclusion}


Facilitated modelling with discrete-event simulation opens a real opportunity for simulations to engage clients in a workshop environment leading to genuine improvements in the real world. The operational research literature demonstrates how powerful facilitated modelling can be, especially in situations where the problem is ill-defined and messy, there is subjectivity, improvements only need to be satisficing, and implementation will be enhanced by the participation of the clients in the study. The animated display of a discrete-event simulation model creates real potential for engaging clients, but the need for detailed complexity in the simulation model is a significant barrier to full facilitated modelling (building the model with the client).

We argue that the primary solution to this problem is not a technical one, but one of changing the worldview of discrete-event simulation modellers. To move away from solely building detailed and hopefully accurate models, to developing simple, less accurate, models for facilitating understanding and debate, and for identifying improvements.

Further work is required to enable a full facilitated modelling approach with simulation. In particular, for the context in which we have worked (lean improvement workshops in a hospital setting) we suggest that integrated software is required that will support group process mapping, data and rule entry, and simulation model generation. We also need to see methodological developments in terms of how best to facilitate a workshop-based modelling session with simulation. What is the right level of model detail? What steps does a facilitator need to follow? What is the best balance in the discussion between the nature of the simulation and the nature of the problem? How much does the process need to be adapted if the discussion is around a planned system rather than on improving a system that already exists? What if the generated simulation is clearly wrong? Can it still be used for generating understanding and debate about the real system? Or should there be an iterative process of improving the model? These questions provide potential for a rich vein of future research into facilitated modelling with discrete-event simulation.

The way forward may be very similar to that experienced by the field of system dynamics in group model building over the last 20 or more years (Andersen et al, 2007). Presently, in discrete-event simulation, we are very little further forward than a concept with a handful of case examples that demonstrate its potential. To develop a facilitated modelling approach 
further we need to see two parallel streams of work. First we need to perform further case examples in which discrete-event simulation is used in a facilitated mode. Then, based upon the learning gained from these cases and other facilitated modelling fields, we need to develop the methodology of a facilitated mode for simulation.

\section{Acknowledgements}

The financial support of the Strategic Lean Implementation Methodology (SLIM) project (www2.warwick.ac.uk/fac/soc/wbs/projects/slim) is acknowledged. SLIM was funded by the Warwick Innovative Manufacturing Research Centre (EPSRC grant reference EP/G049971/1). We are grateful for the advice and support of Matthew Cooke, Neil Davis and Ruth Davies. 


\section{References}

Ackerman, F. and Eden, C. (2010). Strategic Options Development and Analysis. In Systems Approaches to Managing Change: A Practical Guide (M. Reynolds and S. Holwell, eds.), Springer, London: 135-190.

Adamides, E.D. and Karacapilidis, N. (2006). A Knowledge Centred Framework for Collaborative Business Process Modelling. Business Process Management Journal, 12 (5), $557-575$.

Andersen, D.F., Vennix, J.A.M., Richardson, G.P. and Rouwette, E.A.J.A. (2007). Group Modeling building: Problem Structuring, Policy Simulation and Decision Support. Journal of the Operational Research Society, 58 (5): 691-694.

Banks, J., Carson II, J.S., Nelson, B.L. and Nicol, D.M. (2005). Discrete-Event System Simulation. $4^{\text {th }}$ ed. Prentice Hall: Upper Saddle River, NJ.

Barjis, J. (2011). CPI Modeling: Collaborative, Participative, Interactive Modeling. Proceedings of the 2011 Winter Simulation Conference (S. Jain, R.R. Creasey, J. Himmelspach, K.P. White, and M. Fu, eds.), IEEE, Piscataway, NJ: 3099-3108.

Burgess, N., Worthington C., Davis, N., Radnor, Z., Robinson, S., Cooke, M. (2011). SimLean Healthcare: Handbook. www.simlean.org (accessed February 2012). SimLean Publishing. Checkland, P.B. (1981). Systems Thinking, Systems Practice. Wiley: Chichester, UK.

Churchman, C.W. and Schainblatt, A.H. (1965). The Researcher and the Manager: A Dialectic of Implementation. Management Science, 11 (4): B69-B87.

Chwif, L., Barretto, M.R.P. and Paul, R.J. (2000). On Simulation Model Complexity. Proceedings of the 2000 Winter Simulation Conference (Joines, J.A., Barton, R.R., Kang, K. and Fishwick, P.A., eds.), IEEE, Piscataway, NJ: 449-455.

den Hengst, M., de Vreede, G.J. and Maghnouji, R. (2007). Using Soft OR Principles for Collaborative Simulation: A Case Study in the Dutch Airline Industry. Journal of the Operational Research Society, 58 (5): 669-682.

Eskinasi, M., rouwette, E. and Vennix, J. (2009). Simulating Urban Transformation in Haaglanden, the Netherlands. System Dynamics Review, 25 (3): 182-206.

Franco, L.A. and Montibeller, G. (2010). Facilitated Modelling in Operational Research. European Journal of Operational Research, 205(3): 489-500.

Innis, G. and Rexstad, E. (1983) Simulation Model Simplification Techniques. Simulation, 41 (1): 7-15. 
Kotiadis, K. and Mingers, J. (2006) Combining PSMs with Hard OR Methods: The Philosophical and Practical Challenges. Journal of the Operational Research Society, 57 (7): 856-867.

Kotiadis, K. (2007). Using Soft Systems Methodology to Determine the Simulation Study Objectives. Journal of Simulation, 1 (3): 215-222.

Law, A.M. (2007). Simulation Modeling and Analysis, $4^{\text {th }}$ ed. McGraw-Hill, New York.

Lehaney, B. and Paul, R.J. (1996). The Use of Soft Systems Methodology in the Development of a Simulation of Out-Patients Services at Watford General Hospital. Journal of the Operational Research Society, 47: 864-870.

Lehaney, B., Clarke, S.A. and Paul, R.J. (1999). A Case of an Intervention in an Outpatients Department. Journal of the Operational Research Society, 50: 877-891.

Lucas, T.W. and McGunnigle, J.E. (2003). When is Model Complexity too Much? Illustrating the Benefits of Simple Models with Hughes' Salvo Equations. Naval Research Logistics, 50: $197-217$

McKay, J. And Marshall, P. (2001). The Dual Imperatives of Action Research. Information Technology and People, 14 (1): 46-59.

Mingers, J. and Brocklesby, J. (1997). Multimethodology: Towards a Framework for Mixing Methodologies. Omega, 25: 489-509.

Montibeller, G. (2007). Action-Researching MCDA Interventions. In Keynote Papers, $49^{\text {th }}$ Operational Research Society Conference (OR49) (D. Shaw, ed.), Operational Research Society, Birmingham, UK: 106-123.

Phillips, L.D. (1984). A Theory of Requisite Decision Models. Acta Psychologica, 56: 29-48. Pidd M (2004). Computer Simulation in Management Science, $5^{\text {th }}$ ed. Wiley: Chichester, UK.

Pidd, M. and Robinson, S. (2007). Organising Insights into Simulation Practice. Proceedings of the 2007 Winter Simulation Conference (Henderson, S.G., Biller, G., Hsieh, M.-H., Shortle, J., Tew, J.D., Barton, R.R., eds.), IEEE, Piscataway, NJ: 771-775.

Richardson, G.P. and Andersen, D.F. (1995). Teamwork in Group Model Building. System Dynamics Review, 11: 113-137.

Robinson, S. (2001). Soft with a Hard Centre: Discrete-Event Simulation in Facilitation. Journal of the Operational Research Society, 52 (8): 905-915.

Robinson, S. (2002). Modes of Simulation Practice: Approaches to Business and Military Simulation. Simulation Practice and Theory, 10: 513-523.

Robinson, S. (2004). Simulation: The Practice of Model Development and Use. Wiley, Chichester, UK. 
Robinson, S. (2005). Discrete-Event Simulation: From the Pioneers to the Present, What Next? Journal of the Operational Research Society, 56 (6): 619-629.

Robinson, S., Radnor, Z.J., Burgess, N. and Worthington, C. (2012). SimLean: Utilising Simulation in the Implementation of Lean in Healthcare. European Journal of Operational Research, 219: 188-197.

Rosenhead, J. and Mingers, J. (2001). Rational Analysis for a Problematic World Revisited: Problem Structuring Methods for Complexity, Uncertainty and Conflict. Wiley, Chichester, UK.

Rouwette, E.A.J.A. (2011). Facilitated Modelling in Strategic Development: Measuring the Impact on Communication, Consensus and Commitment. Journal of the Operational Research Society, 62: 879-887.

Rouwette, E.A.J.A., Korzilius, H., Vennix, J.A.M. and Jacobs, E. (2011). Modeling as Persuasion: The Impact of Group Model Building on Attitudes and Behavior. System Dynamics Review, 27 (1): 1-21.

Roy, B. (1993). Decision Science or Decision-Aid Science? European Journal of Operational Research, 66: 184-203.

Sachdeva, R., Williams, T. and Quigley, J. (2007). Mixing Methodologies to Enhance the Implementation of Healthcare Operational Research. Journal of the Operational Research Society, 58 (2): 159-167.

Salt, J. (1993). Simulation Should be Easy and Fun. Proceedings of the 1993 Winter Simulation Conference (Evans, G.W., Mollaghasemi, M., Russell, E.C., Biles, W.E., eds.), IEEE, Piscataway, NJ: 1-5.

Sargent, R.G. (2011). Verification and Validation of Simulation Models. Proceedings of the 2011 Winter Simulation Conference (S. Jain, R.R. Creasey, J. Himmelspach, K.P. White, and M. Fu, eds.), IEEE, Piscataway, NJ: 183-198.

Tako, A.A., Kotiadis, K. and Vasilakis, C. (2010). A Participative Modelling Framework for Developing Conceptual Models in Healthcare Simulation Studies. Proceedings of the 2010 Winter Simulation Conference (B. Johansson, S. Jain, J. Montoya-Torres, J. Hugan, and E. Yücesan, eds.), IEEE, Piscataway, NJ: 500-512.

Tako, A.A. and Robinson, S. (2010). Model Development in Discrete-Event Simulation and System Dynamics: An Empirical Study of Expert Modellers. European Journal of Operational Research, 207: 784-794.Thomas, A. and Charpentier, P. (2005). Reducing Simulation Models for Scheduling Manufacturing Facilities. European Journal of Operational Research, 161 (1): 111-125. 
Vennix, J.A.M. (1995). Building Consensus in Strategic Decision Making: System Dynamics as a Group Support System. Group Decision and Negotiation, 4: 335-355.

Vennix, J.A.M. (1996). Group Model Building: Facilitating Team Learning using System Dynamics. Wiley: Chichester, UK.

Vennix, J.A.M., Akkermans, H.A. and Rouwette, E.A.J.A. (1996). Group Model-Building to Facilitate Organizational Chanhe: An Exploratory Study. System Dynamics Review, 12 (1): $39-58$.

Videira, N., Antunes, P., Santos, R. and Lopes, R. (2010). A Participatory Modelling Approach to Support Integrated Sustainability Assessment Processes. Systems Research and Behavioural Science, 27 (4): 446-460.

Ward, S.C. (1989). Arguments for Constructively Simple Models. Journal of the Operational Research Society, 40 (2): 141-153.

Yin, R. K. (1994). Case Study Research: Design and Methods. Beverly Hills, Sage. 